\title{
The assessment of the HSR impacts on Spanish tourism: an approach based on multivariate panel data analysis
}

\author{
Begoña Guirao Abad \\ Associate Professor, UPM, Spain \\ Juan Luis Campa Cascales \\ $\mathrm{PhD}$. Candidate, UPM, Spain \\ María Eugenia López-Lambas \\ Associate Professor, UPM, Spain
}

\begin{abstract}
Literature review shows that little research has done so far to estimate how tourism indicators are affected by new HSR lines. In 2012, a multivariate panel analysis developed by Chen and Haynes was applied to the Chinese regions to quantify the HSR impact on tourism output. The Chinese experience confirmed that, during the period 1999-2010, emerging high speed rail services did have significant positive impacts on boosting tourism in China. Since them, no similar empirical tool has ever been tested in Europe.
\end{abstract}

The aim of this paper is to analyze and validate the suitability of this tool to assess empirically the effects of HSR on Spanish tourism during the period 1999-2014, and to enhance the abovementioned model with a tourism database. With more than 20 years' HSR experience, and operating the longest HSR network in Europe $(2,900 \mathrm{~km})$, Spain offers a good scenario for this model application because Spanish tourism sector represents $10.2 \%$ of its gross domestic product (GDP). Results clearly show that there is a direct linkage between the evolution of certain Spanish tourism outputs and the construction of the HSR network. However, authors' recommendations include future new research on some variables limitations like the type of tourism output considered or the consideration of alternative explanatory indicators.

\section{HSR IMPACTS ON TOURISM: LITERATURE REVIEW}

In a climate of worldwide financial crisis, the exorbitant cost of building a new HSR line requires empirical evidence of its economic and social efficiency and this fact has generated a great debate in the scientific community (Coto-Millán et al., 2007; de Rus and Nombela; 2007 Betancor and Llobet, 2015; Albalate and Bel, 2015; Albalate et al, 2015) Especially in countries with high tourism attractiveness, future HSR line projects need all possible benefits to be studied. Tourism impacts on HSR could be considered as a benefit variable although we recognize that tourism is a complex phenomenon to analyze (Sinclair and Stabler, 1997; Caccomo and Solonandrasana, 2001), a form of complementary demand for which the main 
components are transport, food, and accommodation (Morley, 1992). The link between tourism and transportation infrastructure has been widely analyse in the literature (Khadaroo and Seetanah, 2007, 2008) and there is a general feeling that an increase in the accessibility to the tourism destination usually leads to an increase in tourism demand. But HSR is a relatively new mode of transportation and represents a contemporary revolution in transportation technology which has been promoted only in some countries around the world. For that reason, although literature review shows how tourism has affected HSR demand (Guirao and Campa, 2015), little research has done so far to empirically estimate the opposite effect: how tourism indicators are affected by new HSR lines, which is the main goal of this paper. The majority of published studies describe specific HSR experiences, mainly study cases (Guirao and Soler, 2008; Bazin et al., 2011) and some observed HSR effects on tourism but, as it is described below, they do not lead to a general conclusion.

Using destination choice, Delaplace et al. (2014) studied HSR impacts in Paris and Rome tourism. On the basis of a survey of tourists, data collected from the two surveys were used for a quantitative analysis using regression models and results demonstrated that HSR influences destination choice in different ways in the two cities, being in Paris the tourism more dependent on HSR. This interesting contribution was completed by Pagliara et al. (2015a, 2015b) using Madrid case study. Although these results are quite clarifying, the approach that destination choice may be influenced by HSR is no proof that a new line will automatically promote a tourist destination or increase tourist-sector revenues in this city (accommodation, restaurants, museums and so on).

Masson and Petiot (2009) used an economic geographic model (Krugman, 1991), to discuss the influence of the southern European high speed rail (HSR) between Perpignan (France) and Barcelona (Spain) on both tourism activity and economic development. Using a nonempirical discussion, they argued that HSR can facilitate the development of tourism activities, and particularly business and urban tourism. With a similar methodology, using a gravitational model (the iso-tourist line from a time-space replacement concept) Wang et al. (2012) studied in China the projected HSR effects on tourism: redistribution and transformation of the tourist market, market competition on a larger scale, and reallocation of the urban tourism centre. But the methodology developed by Wang et al. was not empirical and did not allow the estimation of tourism ouput, like tourism demand or tourism revenue.

Apart from economic geography models and the choice destination approach, the existing literature on tourism demand is dominated by econometric models that tend to follow a single-equation panel data approach (Lim, 1997; Song and Li, 2008; Song and Wong, 2003). Chen and Haynes (2012) were the first to apply this methodology to HSR impact on tourism. Through a multivariate panel analysis, they investigated the impact of Chinese high-speed rail systems on the tourism industry, selecting only the numbers of incoming foreign tourists and tourism revenue as the dependent variables. This experience confirmed that, during the 
period 1999-2010, emerging high speed rail services did have significant positive impacts on boosting tourism in China. I

In this context, the study of the suitability of the Chen and Haynes's tool when applied to other European case studies seems to be the more reasonable first step towards the development of a systematic tool to evaluate the integral impact of HSR on the tourism industry. The man aim of this research lies in the first assessment of the dynamic panel data model tested in the Chinese scenario when applied to a European country: Spain. This paper is divided into the following parts: first, literature review in section 1; description and results of the model tested in China (section 2), application to the Spanish case study (section 4); and finally, the main conclusions (section 4).

\section{THE CHINA CASE STUDY}

The model proposed by Chen and Haynes (2012) is based on a multivariate panel analysis using the data from 1999 to 2010 at the provincial level. Due to China's large population and area, the administrative divisions of China have consisted of several levels since ancient times. The regional and geographic characteristics in the east and west, north and south vary substantially and the selected unit of analysis by Chen and Haynes was the provincial level, which includes 27 provinces and 4 municipalities. Table 1 shows variables (and their main descriptive statistics) used by Chen and Haynes in their model.

In relation to the dependent variables, the criteria used by authors to select the tourism output were focused on the the availability of the related data base: number of foreign tourist arrivals (taf), number of oversea tourist arrivals (tat) and tourism revenue (tr). Three different models, using the same structure and independent variables but different tourism output, were tested in order to quantify the impact of the HSR lines on China tourism. It is important to remark that domestic tourism demand data was not publicly available and was not considered in the research and this is an important drawback of the methodology. Moreover, the numbers of total oversea tourist arrivals differs from the numbers of foreign tourist arrival in that the former not only includes the later, but also tourists from Macau, Hong Kong and Taiwan. Fortunately, tourism revenue output includes revenues from total oversea tourist arrivals.

In relation to explanatory variables (dependent variables), rail features are defined by three indicators: lengtht of the railway network (including conventional lines), rail traffic (ridership) and the presence of HSR lines in each province (dummy variable). A preliminary multicollinearity data analysis found that the correlations among two of these rail variables (rail length and ridership) were not low and this fact forced the authors to present two separated models per tourism output (see Equations 1 and 2).

In relation to the rest of independent variables, authors used two economic indicators: the 
annual nominal exchange rate (exc) from US dollar to RMB (RenMinBi, thelegal tender of China) and the Gross Provincial Product per capita (gpppc). Some multidimensional features of local tourism are also collected: number of World Heritage Sites, number of scaled restaurants, number of museums, or number of public libraries (lib). Impedance variables were also took into account as the number of accidental pollution releases or the dummy variable associated to the outbreak of SARS (Severe Acute Respiratory Syndrome), originated in China in 2003. Attracting dummy variables were also considered to control the influences of events, like the 2008 Beijing Olympic Games and the 2010 Shanghai Expo respectively. Finally, there is another additional variable in the model (called year, that does not appear in Table 1), which finally collects the sequence of the observations (372 valid observations) and tries to measure time trends.

\begin{tabular}{|c|l|r|r|}
\hline Variables & Definition & Mean & \multicolumn{1}{l|}{ S.D. } \\
\hline tat & Numbers of total oversea tourist arrivals (10,000 persons) & 173.271 & 359.405 \\
\hline tat & Numbers of foreign tourist arrivals (10,000 persons) & 94.425 & 120.324 \\
\hline tr & Tourism revenue from oversea tourist arrivals (2005 million \$) & 822.995 & 1419.954 \\
\hline rider & Passenger railway ridership (10,000 persons) & 3946.763 & 2847.747 \\
\hline rlen & Railway length (kilometer) & 2396.565 & 1517.768 \\
\hline gpppc & Gross Provincial Product per capita (2005 \$) & 2159.243 & 1690.715 \\
\hline hotel & Numbers of five-stars hotel & 9.202 & 12.445 \\
\hline resta & Numbers of scaled restaurant & 357.952 & 521.354 \\
\hline whs & Numbers of World Heritage Sites & 2.118 & 3.217 \\
\hline artc & Numbers of art center & 62.263 & 44.397 \\
\hline lib & Numbers of library & 89.105 & 42.915 \\
\hline museum & Numbers of museum & 54.358 & 37.288 \\
\hline exchange & Exchange rate (US \$ to RMB) & 7.831 & 0.600 \\
\hline pollution & Numbers of environmental accidents & 41.570 & 67.786 \\
\hline SARS & A dummy variable which equals one for the year of 2003 & 0.083 & 0.277 \\
\hline BJolympic & A dummy variable which equals one for the year of 2008 & 0.083 & 0.277 \\
\hline SHExpo & A dummy variable which equals one for the year of 2010 & 0.083 & 0.277 \\
\hline HSR & A dummy variable which equals one for the year and province & 0.083 & 0.277 \\
& thathas a HSR service & & \\
\hline
\end{tabular}

\section{Table 1 - Descriptive Statistics of Variables used in the Chinese case study (Chen and Haynes, 2012)}

Equations 1 and 2 shows the structure of the models, which were implemented using a fixed effects (FE) formulation (to take into account the unobserved individual effects). The subindices $i$ and $t$ denote tour destination provinces and time period respectively while $Y$ represents the dependent variables (foreign tourist arrivals, total overseas tourist arrivals or total overseas tourist revenue). Consequently, three pairs of estimations were carried out by Chen and Haynes and the error term $\varepsilon_{i t}$ is the sum of the unobserved province-specific effects $\mu_{\mathrm{i}}$ and the white noise error term $v_{i t}$. The results of the application of the six models ( 2 per tourism output) demonstrate the effectiveness of Chen and Haynes' estimation. The adjusted $\mathrm{R}$ square of the 6 models range between 0.67 and 0.81 , indicating that the selected variables can explain between 67 to 81 percent of variances of the different tourism outputs. 
Equation 1

$$
\begin{aligned}
\operatorname{lnY}_{i t}=\alpha_{1} & +\beta_{1} \ln \text { rider }_{i t}+\beta_{2} \ln \text { gpppc }_{i t}+\beta_{3} \ln \text { hotel }_{i t}+\beta_{4} \ln r e s t a_{i t}+\beta_{5} \text { whs }_{i t}+\beta_{6} \text { art }_{i t}+\beta_{7} \text { lib }_{i t} \\
& +\beta_{8} \text { museum }_{i t}+\beta_{9} \text { pollution }_{i t}+\beta_{10} \text { SARS }_{t}+\beta_{11} \text { BJolympic }_{t}+\beta_{12} \text { SHexpo }_{13}+\beta_{13} \text { Year } \\
& +\beta_{14} \text { HSR }+\varepsilon_{i t}
\end{aligned}
$$

Equation 2

$$
\begin{aligned}
\operatorname{lnY}_{i t}=\alpha_{1} & +\beta_{1} \ln \text { rlen }_{i t}+\beta_{2} \ln \text { gpppc }_{i t}+\beta_{3} \ln \text { hotel }_{i t}+\beta_{4} \ln \text { resta }_{i t}+\beta_{5} \text { whs }_{i t}+\beta_{6} \text { artc }_{i t}+\beta_{7} \text { lib }_{i t} \\
& +\beta_{8} \text { museum }_{i t}+\beta_{9} \text { pollution }_{i t}+\beta_{10} \text { SARS }_{t}+\beta_{11} \text { BJolympic }_{t}+\beta_{12} \text { SHexpo }_{13}+\beta_{13} \text { Year } \\
& +\beta_{14} \text { HSR }+\varepsilon_{i t}
\end{aligned}
$$

Among the results obtained, surprisingly, the local site characteristics such as numbers of five stars hotels, high scale restaurants, world heritage sites and museums are not statistically significant in all the tested models. Only the deterrent destination variable SARS shows a strong significant but negative impact on all the tourism outputs while the number of pollutions is not statistically significant. On the other hand, the used origin variable, the exchange rate (exc), results a key determinant on tourism outputs together with the destination gross provincial product per capita (gpppc) variable.

In relation to rail variables, and this is the main result obtained by Chen and Haynes, the key policy variable HSR is the most relevant, being statistically significant at $5 \%$ significance level. For instance, if the province has the HSR service, it is likely to have an additional 20 percent of foreign visitors, or 23 percent total oversea visitors, or 25 percent total oversea revenue in that year. With these findings, the authors confirm that HSR services do have a significant influence on promoting tourism but recognize the validity of previous HSR investments only in that particular time and spatial context. China results have encouraged authors of this paper to study the implementation of the multivariate panel data analysis to Spain. Immediately after, next section contains a demonstration and discussion of the modelling process and the results for the Spanish case.

\section{SPAIN CASE STUDY}

The direct application of Chen and Haynes's tool to the Spanish case raises several difficulties, mainly associated to the adaptation of the statistical database to the variables used in the original model. In order to use similar criteria, a provincial level data base was considered and 47 provinces were selected (after removing those located on the Spanish islands). The multivariate panel analysis was carried out taking into account the data base limitations and the period from 1999 to 2015 was selected for the study. In accordance with the original model, the dependent variables were focused on similar tourism demand indicators: number of foreign (Non Resident in Spain) tourists (taNR) and tourism revenue from not resident in Spain tourists (tr). Unlike China, domestic tourism demand data is publicly available in Spain by INE (Instituto Nacional de Estadística), but in order to compare similar results (between the Chinese and the Spanish experience) the panel data 
analysis was not applied to domestic tourism. It is important to remark that the term used by INE is "number of tourists" and the correspondent figures are calculated using the data of overnight stays provided by hotels. Table 3 shows the list of variables (and their main descriptive statistics) introduced in the Spanish models. Apart from the local economic variable used by Chen and Haynes, the Gross Provincial Product per capita (gpppc), a great effort was devoted to collect the same multidimensional features of local tourism used in the original model: number of World Heritage Sites, number of scaled restaurants, number of museums and number of public libraries (art centers were included in the number of museums).

\begin{tabular}{|c|l|c|c|}
\hline Variables & Definition & Mean & S.D. \\
\hline taNR & Number of foreign (non-resident in Spain) tourists (10.000 persons) & 48.620 & 98.684 \\
\hline tr & Tourism revenue from foreign tourists (1999 million \$) & 494.736 & 963.052 \\
\hline rider & Railway ridership (10,000 people) & $2,122.441$ & 421.862 \\
\hline rlen & Railway length (Km.) & $14,713.679$ & $1,383.290$ \\
\hline gpppc & Gross Provincial Product per capita (1999 € x 1000) & 15.672 & 3.543 \\
\hline hotel & Numbers of four-star and five-star hotel & 23.671 & 33.542 \\
\hline whs & Numbers of World Heritage Sites & 0.721 & 0.750 \\
\hline lib & Number of libraries & 133.146 & 124.466 \\
\hline museum & Number of museums & 29.731 & 31.844 \\
\hline exchange & $\begin{array}{l}\text { Difference between Gross Product per capita in Euro Zone and the } \\
\text { Spanish Provincial value (1999 } € \text { x 1000) }\end{array}$ & 1.983 & 4.329 \\
\hline Forum & Dummy variable which equals one for the year of 2004 & 0.059 & 0.235 \\
\hline AmCup & Dummy variable which equals one for the year of 2007 & 0.059 & 0.235 \\
\hline ExpoZ & Dummy variable which equals one for the year of 2008 & 0.059 & 0.235 \\
\hline HSR & $\begin{array}{l}\text { Dummy variable which equals one for the year and province that has } \\
\text { a HSR service }\end{array}$ & 0.214 & 0.410 \\
\hline
\end{tabular}

Table 2 - Descriptive Statistics of Variables used in the Spanish case study.

In the time period considered (1999-2015) no special impedance variables were took into account, like the Chinese accidental pollution releases or the outbreak of diseases of SARS. Instead, three special dummy variables related to the promotion of big international cultural and sports events were introduced as attracting indicators: the Forum 2004 held in Barcelona (Forum), the case of Valencia and the America's Cup in 2007 (AmCup), and finally the case of the International Exhibition in Zaragoza held in 2008 (expoZ). There is another additional variable in the model (called year), not linked to origin, destination or policy features, which finally collects the sequence of the observations and tries to measure time trends.

In case of China, authors only used the annual nominal exchange rate (exc) from US dollar to RMB (RenMinBi), but this variable has been modified in the Spain case study. According to the statistics of foreign tourism (Instituto Español de Turismo, 2009), more than $75 \%$ of the Spanish foreign tourism is coming from the European Union and for that reason, our exchange variable has been defined as the difference between the provincial GDP and the European (Eurozone) GDP, referring currency to year 1999. Other modifications from the original model have to do with the type of hotels considered in the analysis: in Spain, four star hotels are the most demanded ones for both domestic and foreign visitors (Instituto Español de Turismo, 2015), and for that reason the hotel variable (hotel) has included the 
number of 4 and 5 star hotels (China case study only included 5-star hotels).

In relation to the unobserved individual effect in a panel model, four fixed effects model (FE) were developed, which consisted in statistical models that represents the observed quantities in terms of explanatory variables that are treated as if the quantities were nonrandom. Table 3 shows the determinants of foreign tourism in Spain obtained from model 1 (using rail network length) and a comparison with Chen and Haynes findings using the same tourism output.. The Tables 3-6 shows the determinants of tourism output in Spain obtained from the model 1-4 (using rail ridership or rail length) and a comparison with Chen and Haynes results.

\begin{tabular}{|c|c|c|c|}
\hline \multicolumn{4}{|c|}{ Model 1} \\
\hline \multicolumn{2}{|c|}{ China Case Study } & \multicolumn{2}{|c|}{ Spain Case study } \\
\hline \multirow[t]{2}{*}{ Dependent } & Ltaf & \multirow[t]{2}{*}{ Dependent } & \multirow{2}{*}{$\mathrm{FE}$} \\
\hline & $\mathrm{FE}$ & & \\
\hline Lrider & $0.082 \quad(0.107)$ & lrider & $1.626(3.745)$ \\
\hline Lrlen & & Irlen & \\
\hline Lgpppc & $0.459 * * \quad(0.222)$ & lgpppc & $3.000 * * * \quad(0.755)$ \\
\hline Lhotel & $\begin{array}{ll}0.078 \quad(0.050) \\
\end{array}$ & lhotel & $0.938^{* * *}(0.030)$ \\
\hline Lresta & $0.054 \quad(0.054)$ & & \\
\hline Whs & $-0.003(0.010)$ & whs & $0.003 \quad(0.010)$ \\
\hline Artc & $0.000 \quad(0.001)$ & & \\
\hline $\mathrm{Lib}$ & $-0.001 \quad(0.002)$ & lib & $0.071 * * * \quad(0.018)$ \\
\hline Museum & $-0.002 \quad(0.001)$ & museum & $-0.027 * * \quad(0.013)$ \\
\hline Exchange & $0.241 * * * \quad(0.078)$ & exchange & $0.084 * * \quad(0.033)$ \\
\hline Pollution & $0.000 \quad(0.000)$ & & \\
\hline SARS & $-0.447 * * * \quad(0.057)$ & Forum & $-0.002 \quad(0.003)$ \\
\hline Bjolumpic & $0.028 \quad(0.066)$ & AmCup & $-0.002 \quad(0.002)$ \\
\hline Shexpo & $-0.055 \quad(0.069)$ & ExpoZ & $-0.003 \quad(0.003)$ \\
\hline Year & $0.089 * * * \quad(0.024)$ & Year & $-17.887 \quad(24.957$ \\
\hline HSR & $0.201 * * \quad(0.073)$ & HSR & $0.012 * * \quad(0.005)$ \\
\hline Cons & $-180.954 * * * \quad(46.067)$ & cons & $13.186 \quad(22.706$ \\
\hline R-adj & 0.810 & R-adj & 0.744 \\
\hline No. Of obs & 313 & No. Of obs & 799 \\
\hline
\end{tabular}

Table 3. Determinants of foreign tourism e in Spain obtained from model 1 (using rail ridership rider). Comparison with Chen and Haynes results (2012)

The first finding, in the Spanish case, is related to the local site characteristics such as numbers of five stars hotels, high scale restaurants, world heritage sites and museums. In China, these variables were not statistically significant in any of the designed models, while in Spain, there are some indicators, like the hotel variable, which are statistically significant at $1 \%$ level. The coefficients of the hotel variable, considering the four models, range between 0.941 and 0.591 . Other local site characteristics, like museums or libraries reached high levels of significance, although their coefficients are much lower than hotel variable values. 
The insignificant results for the event variables are similar for the Chinese and the Spanish experience. The special events such as the 2008 Beijing Olympic Game and the 2010 Shanghai Expo and number of pollution incidents are not statistically significant even at the $1 \%$ level. However, in China, the year dummy of 2003, which represents the epidemic of SARS in that year, is highly statistically significant. The estimation makes sense since SARS has a reasonably strong negative effect on foreign tourist arrivals In the Spanish model no deterrent event variable was introduced and results are consistent with the Chinese results.

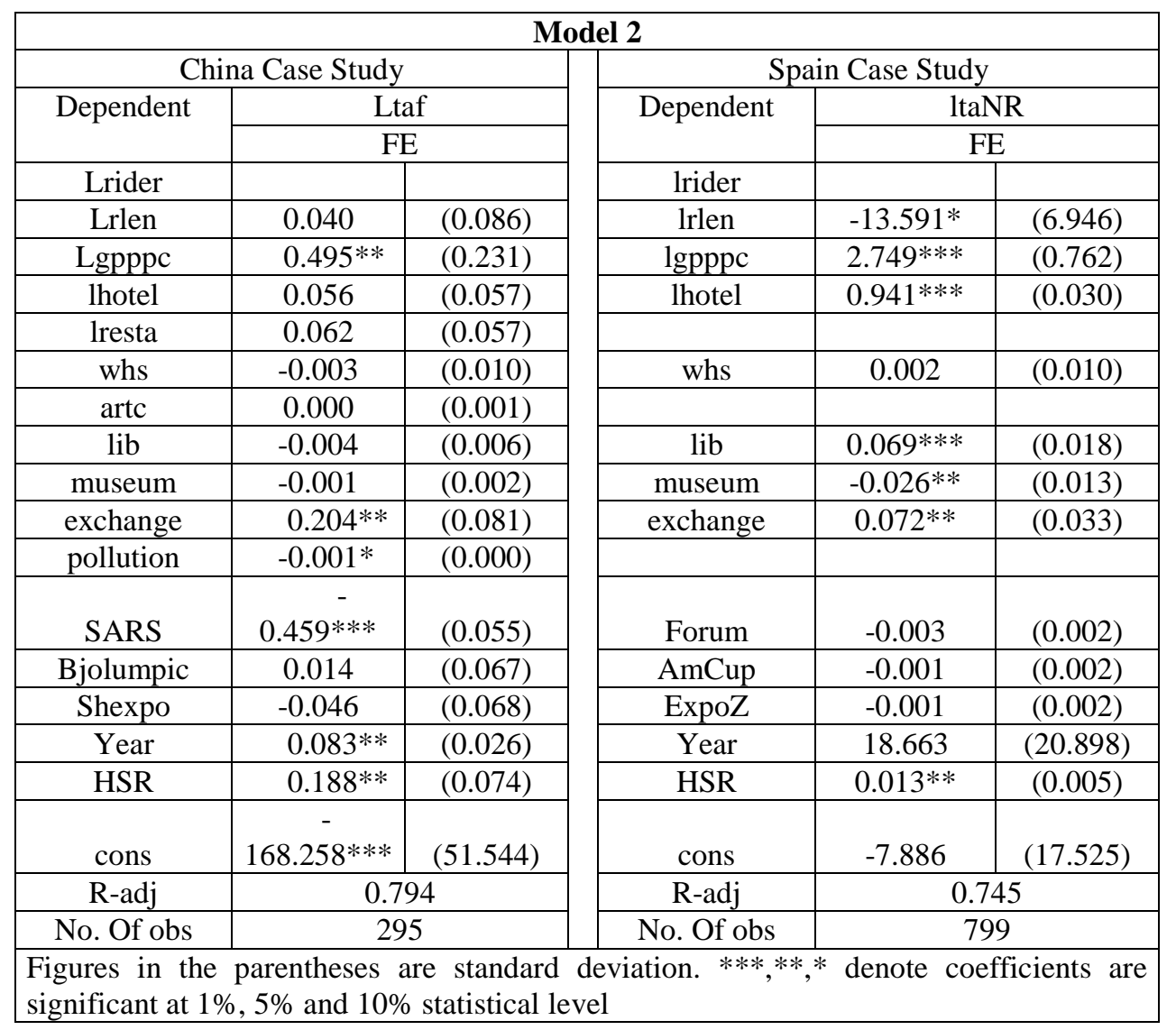

Table 4. Determinants of foreign tourism in Spain obtained from model 2 (using length). Comparison with Chen and Haynes results (2012)

Among all the explanatory variables, it is not surprising to find that the gross provincial product per capita (gpppc) variable has a significant impact on the number of foreign tourists, either in China or in Spain. In China, the elasticities are 0.459 and 0.495 , which can be interpreted as a one percent increase in the gpppc is associated with around a 0.46 to 0.5 percent increase in foreign tourist arrivals. In Spain, the level of significance of the variable is even higher (1\%) for the foreign tourism output together with the coefficients. In contrast, for the Spanish revenue output models, the gross provincial product per capita is not significant and that means that in Spain, the tourist expense in richer provinces is higher than in poorer ones (hotels and restaurants use to be more expensive). 
Another key determinant is the exchange rate (exc), which represents the price level of tourism. In the case of China, a decrease of exc denotes the appreciation of RMB and a depreciation of US dollars, in other words, the price of a Chinese tour rises. On the contrary, the increase of exc would indicate the decrease of tour price in China, which thus may further attract more international tourists. This variable is less significant than the gross provincial product per capita (gpppc) and in the revenue models, either in China or Spain, is not important (in terms of significance).

\begin{tabular}{|c|c|c|c|c|c|}
\hline \multicolumn{6}{|c|}{ Model 3} \\
\hline \multicolumn{3}{|c|}{ China case study } & \multicolumn{3}{|c|}{ Spain case study } \\
\hline \multirow[t]{2}{*}{ Dependent } & \multicolumn{2}{|c|}{ Ltr } & \multirow[t]{2}{*}{ Dependent } & \multicolumn{2}{|c|}{ ltr } \\
\hline & \multicolumn{2}{|c|}{$\mathrm{FE}$} & & \multicolumn{2}{|c|}{$\mathrm{FE}$} \\
\hline lrider & 0.074 & $(0.113)$ & lrider & 0.269 & $(3.173)$ \\
\hline lrlen & & & lrlen & & \\
\hline lgpppc & $0.711 * *$ & $(0.234)$ & lgpppc & 0.637 & $(0.640)$ \\
\hline lhotel & 0.055 & $(0.053)$ & lhotel & $0.591 * * *$ & $(0.025)$ \\
\hline lresta & 0.037 & $(0.057)$ & & & \\
\hline whs & 0.008 & $(0.010)$ & whs & $-0.040 * * *$ & $(0.008)$ \\
\hline artc & 0.000 & $(0.001)$ & & & \\
\hline lib & -0.002 & $(0.002)$ & lib & $0.077 * * *$ & $(0.015)$ \\
\hline museum & -0.002 & $(0.002)$ & museum & -0.005 & $(0.011)$ \\
\hline exchange & 0.130 & $(0.083)$ & exchange & 0.013 & $(0.028)$ \\
\hline pollution & 0.000 & $(0.000)$ & & & \\
\hline SARS & $-0.439 * * *$ & $(0.060)$ & Forum & -0.002 & $(0.003)$ \\
\hline Bjolumpic & -0.081 & $(0.070)$ & AmCup & -0.001 & $(0.002)$ \\
\hline Shexpo & -0.072 & $(0.072)$ & ExpoZ & -0.002 & $(0.003)$ \\
\hline Year & 0.014 & $(0.025)$ & Year & $-46.454 * *$ & $(21.149)$ \\
\hline HSR & $0.254 * * *$ & $(0.077)$ & HSR & $0.017 * * *$ & $(0.004)$ \\
\hline cons & -28.931 & $(48.611)$ & cons & $45.901 * *$ & $(19.242)$ \\
\hline R-adj & \multicolumn{2}{|c|}{0.684} & R-adj & \multicolumn{2}{|c|}{0.638} \\
\hline $\begin{array}{l}\text { No. Of } \\
\text { obs }\end{array}$ & \multicolumn{2}{|c|}{313} & No. Of obs & \multicolumn{2}{|c|}{799} \\
\hline
\end{tabular}

Table 5. Determinants of foreign tourism revenue in Spain obtained from model 3 (using rail ridership rider). Comparison with Chen and Haynes results (2012)

In relation to rail variables, while ridership and length are not really significant, the dummy indicator HSR plays an important role (being statistically significant at $1 \%$ significance level) in the foreign revenue models of China and Spain. This result is the key finding of this paper, although coefficients obtained in Spain are much lower than the ones obtained for China. In China, the highest coefficient is around 0.25 , which can be interpreted as provinces with HSR services in that particular year are associated with approximate 25 percent additional tourism revenue than either year when they do not have the service or the provinces that do not have the services. In Spain, the highest coefficient (see models 3 and 4) is 0.017 , which means that provinces with HSR services in that particular year are associated with approximate 1.7 percent additional tourism revenue than either year when 
they do not have the service or the provinces that do not have the services

\begin{tabular}{|c|c|c|c|c|c|}
\hline \multicolumn{6}{|c|}{ Model 4} \\
\hline \multicolumn{3}{|c|}{ China case study } & \multicolumn{3}{|c|}{ Spain case study } \\
\hline Dependent & \multicolumn{2}{|c|}{ ltr } & Dependent & \multicolumn{2}{|c|}{ ltr } \\
\hline & \multicolumn{2}{|c|}{ FE } & & \multicolumn{2}{|c|}{$\mathrm{FE}$} \\
\hline lrider & & & Lrider & & \\
\hline lrlen & 0,046 & $(0,092)$ & Lrlen & $-14,874 * *$ & $(5,876)$ \\
\hline lgpppc & $0,759 * *$ & $(0,246)$ & Lgpppc & 0,322 & $(0,644)$ \\
\hline lhotel & 0,024 & $(0,061)$ & Lhotel & $0,594 * * *$ & $(0,025)$ \\
\hline lresta & 0,029 & $(0,060)$ & & & \\
\hline whs & 0,004 & $(0,011)$ & whs & $-0,040 * * *$ & $(0,008)$ \\
\hline artc & 0,000 & $(0,001)$ & & & \\
\hline lib & $-0,007$ & $(0,006)$ & lib & $0,074 * * *$ & $(0,015)$ \\
\hline museum & $-0,002$ & $(0,002)$ & museum & $-0,004$ & $(0,011)$ \\
\hline exchange & 0,097 & $(0,086)$ & exchange & $-0,002$ & $(0,028)$ \\
\hline pollution & 0,000 & $(0,000)$ & & & \\
\hline SARS & $-0,444 * * *$ & $(0,059)$ & Forum & $-0,002$ & $(0,002)$ \\
\hline Bjolumpic & $-0,092$ & $(0,071)$ & AmCup & 0,000 & $(0,002)$ \\
\hline Shexpo & $-0,068$ & $(0,072)$ & ExpoZ & $-0,001$ & $(0,002)$ \\
\hline Year & 0,009 & $(0,028)$ & Year & $-14,415$ & $(17,678)$ \\
\hline HSR & 0,256 *** & \begin{tabular}{|l|}
$(0,078)$ \\
\end{tabular} & HSR & $0,017 * * *$ & $(0,004)$ \\
\hline cons & $-18,293$ & $(54,808)$ & cons & $29,331 * *$ & $(14,825)$ \\
\hline R-adj & \multicolumn{2}{|c|}{0,665} & R-adj & \multicolumn{2}{|c|}{0,641} \\
\hline $\begin{array}{l}\text { No. Of } \\
\text { obs }\end{array}$ & \multicolumn{2}{|c|}{295} & No. Of obs & \multicolumn{2}{|c|}{799} \\
\hline
\end{tabular}

Table 6. Determinants of foreign tourism revenue in Spain obtained from model 4 (using rail lenth rlen). Comparison with Chen and Haynes results (2012)

In conclusion, results shows how HSR in Spain has affected positively to foreign tourism (especially revenue coming from foreign tourism), although his impact is not as important as the one registered in China. There are other explanatory variables in the model with identical significance but higher coefficients, like the gross provincial product or the number of hotels. In Spain, HSR serves mainly domestic trips and one of the main drawbacks of the Chen and Haynes's model is that it does not consider domestic tourists, and this percentage is quite high in Europe. Moreover, the HSR impacts on tourism in a country like China, where the alternative interurban transport network is less developed than in Europe, are probably of a higher magnitude and easier to detect by an econometric model. Further research is also needed on using variables related to the territorial distribution of the HSR lines and the services offered by the operating companies. In these commuter touristic relations, for example, most of the visitors do not use to stay at hotels and consequently, they are not registered as tourists by official statistics. In conclusion, the model needs a greater detail of data disaggregation together with a better understanding of the territorial distribution of the HSR lines through new explanatory variables. 


\section{CONCLUSIONS}

Literature review shows how tourism has affected HSR demand but little research has done so far, even in Europe, to empirically estimate the opposite effect: how tourism indicators are affected by new HSR lines. Chen and Haynes were the first ones to investigate the impact of a high-speed rail system on the tourism industry, using a multivariate panel analysis and obtaining positive results: during the period between 1999 and 2010, the emerging highspeed rail services had significantly boosted tourism in China and provinces with high-speed rail services were likely to have approximately 20 percent more foreign arrivals and 25 percent higher tourism revenues than provinces without these systems. One of the main drawbacks of the Chinese analysis is that it did not consider domestic tourism output, which in case of European countries represents an important amount of visitors.

Although China represents a very special context quite different from the European one, a detailed study of the suitability of the Chinese experience seems to be the more reasonable first step towards seeking a new and systematic tool to evaluate the integral impact of HSR on the tourism industry. Authors of this paper has devoted an important effort to adapt the Spanish data base to the variables defined in the China analysis, introducing new variables when necessary and eliminating those not applicable to the Spanish scenario. Four different models were designed using only the number of foreign visitors and foreign revenue as dependent variables.

Comparing the results with China case study, the gross provincial product per capita (gpppc) variable has also in Spain significant impact on the number of foreign tourists, while number of hotels and other local site attracting indicators are more significant in Spain than in China. The HSR variable behavior is a key issue in this paper, being highly significant either in China or in Spain, although coefficients obtained in Spain are much lower than the ones obtained for China In conclusion, results shows how HSR in Spain has affected positively to foreign tourism (especially revenue coming from foreign tourism), although his impact is not as important as the one registered in China. There are other explanatory variables in the model with identical significance but higher coefficients, like the gross provincial product or the number of hotels. In Spain, HSR serves mainly domestic trips and one of the main drawbacks of the Chen and Haynes's model is that it does not consider domestic tourists, and this percentage is quite high in Europe

Nevertheless, it must be highlighted that the most important tourism output considered in the Spain case study (number of foreign tourists) is linked to the stay at hotels. Due to the lack of other national data, like the number of visitors staying in apartments or in second residences, which have not been taken into account by the model, results should be interpreted with caution. Their consideration as well as to deepen in the understanding of the existing impacts should be subject to further research with a new and ad-hoc data base elaboration. The model should distinguish between conventional rail network and HSR 
network, and HSR commuter relations serving some province capitals in Spain should require a special treatment due to the fact that, in these commuter relations, most of the visitors do not use to stay at hotels (then, they are not registered as tourists by official statistics). Finally, the model needs a greater detail of data disaggregation together with a better understanding of the territorial distribution of the HSR lines and the type of HSR service offered by the operating companies. This paper only represents the first step towards a better understanding of the HSR impacts on the tourism industry.

\section{REFERENCES}

ALBALATE, D., BEL, G., 2012. The Economics and Politics of High-Speed Rail. Lessons from Experiences Abroad. Rowman and Littlefield Publishers (Lexington Books), Lanham, MA.

ALBALATE, D., BEL, G., FAGEDA, X., 2015 When supply travels far beyond demand: institutional and regulatory causes of oversupply in Spain's transport infrastructure. Transp. Policy 41, 80-89.

BETANCOR, O. Y G. LLOBET (2015). Contabilidad Financiera y Social de la Alta Velocidad en España. FEDEA, Estudios sobre economía española, no. 2015-08. Madrid, marzo de 2015.

BAZIN, S., BECKERICH, C., DELAPLACE, M., 2011. High speed railway, service innovations and urban and business tourism development, in Sarmento M. \& Matias (editors), A. Economics and Management of Tourism: Trends and Recent Developments. Collecçao Manuais, Universidade Luisiada Editora, Lisboa, Portugal.

CACCOMO, J.L., SOLONANDRASANA, B., 2001. L'innovation dans l'industrie touristique, enjeux et strategies. L'Harmattan, Paris.

CHEN, Z., HAYNES, K.E., 2012. Tourism industry and High Speed Rail, is there a Linkage: evidence from China's High Speed Rail development. ASRDLF, 2012 Conference special session on High Speed Rail, Tourism and Territories, 9th-11th July, Belfort, France.

COTO-MILLAN, P., INGLADA V., REY B., 2007. Effects of network economies in highspeed rail: the Spanish case. The Annals of Regional Science, 41, 4, 911-925.

DELAPlACE M., PAGLIARA, F., PERRIN, J., MERMET, S., 2014. Can High Speed foster the choice of destination for tourism purpose? in Procedia-Social and Behavioral Sciences, 111 (2014), 166-175.

GUIRAO, B., SOLER, F., 2008. Impacts of the new high-speed service on small touristic cities: the case of Toledo, in The Sustainable City V. Urban Regeneration and Sustainability. Wessex Institute of Technology. pp 465-473.

KHADAROO, J., SEETANAH, B., 2007. Transport infrastructure and tourism development. Ann. Tourism Res. 34 (4), 1021-1032.

KHADAROO, J., SEETANAH, B., 2008. The role of transport infrastructure in international tourism development: a gravity model approach. Tourism Manage. 29(5), 831-840.

KRUGMAN, P., 1991. Increasing returns and economic geography. Journal of Political Economy 99(9), 483-499. 
LIM, C., 1997. Review of international tourism demand models, in Annals of Tourism Research, 24-4, 835-849.

MASSON, S., PETIOT, R., 2009. Can the high-speed reinforce tourism attractiveness? The case of the high-speed rail between Perpignan (France) and Barcelona (Spain). In Technovation, n. 29, pp 611-617.

MORLEY, C., 1992. A microeconomic theory of international tourism demand. Annals of Tourism Research 19 (2), 250-267.

PAGLIARA, F., DELAPLACE, M., VASSALlO, J.M., 2015a. High-speed trains and tourists: what is the link? Evidence from the French and Spanish capitals. Urban Transport XX, 138, 17-28.

PAGLIARA, F., LAPIETRA, A. GOMEZ, J., VASSALO, J.M., 2015b. High speed rail and the tourism market: Evidence from the Madrid case study. Transport Policy, 37, 187-194. SINCLAIR, T., STABLER, M., 1997. The Economics of Tourism. Routledge, London. SONG, H., LI, G., 2008. Tourism Demand Modeling and forecasting- A review of recent research, in International Journal of Hospitality Management, 22-4, 435-451.

SONG, H., WONG, K.F., 2003. Tourism demand modelling: a time varying parameter approach, in Tourism Management, 23, 475-487.

WANG, X., HUANG, S., ZOU, T., YAN, H., 2012. Effects of the high speed rail network on China's regional tourism development. Tourism Management Perspectives, 1, 34-38. 